Journal of Mathematics and Statistics 8 (2): 253-257, 2012

ISSN 1549-3644

(C) 2012 Science Publications

\title{
Teachers' Perceptions toward the use of GeoGebra in the Teaching and Learning of Mathematics
}

\author{
Effandi Zakaria and Lo Sooth Lee \\ Department of Educational Methodology and Practices, \\ Faculty of Education, Universiti Kebangsaan Malaysia, Bangi, Selangor, Malaysia
}

\begin{abstract}
Problem statement: In a study by TIMSS, approximately $20 \%$ of Malaysian students failed to achieve the minimum benchmarks in mathematics. In addition, students do not understand mathematical concepts and lack necessary skills in problem-solving. The purpose of this study was to examine teachers' perceptions toward the features and tools in GeoGebra. Approach: A GeoGebra workshop was conducted involving 30 secondary school teachers. This study employed a quantitative survey method that uses a questionnaire to collect data. Descriptive statistics were used to gauge teachers' perceptions toward the software during a GeoGebra workshop. Results: The findings showed that teachers' perceptions toward GeoGebra features were at a moderate level $(\mathrm{M}=3.53)$. Teachers' perceptions toward the basic construction of geometry and the transformation angle were at a high level, with a mean of 3.85 and 3.78. Teachers' perceptions toward coordinates and equations, functions and exporting of images were at a moderate level, with a mean of 3.57 and 3.59. The findings indicate that teachers have positive perceptions toward the use of GeoGebra. Conclusion: Therefore, based on the findings of this study, GeoGebra can and should be used as an alternative to promote the use of technology in the teaching and learning of mathematics.
\end{abstract}

Key words: Transformation, coordinates, GeoGebra, geometry, equations

\section{INTRODUCTION}

In the world of information technology, rapid changes have taken place in education. Intense competition and efforts toward the formation of a world-class education system have also emerged. There has been an increase in the use of multimedia technology, especially computers and special software, in the teaching of science and mathematics. Integrating technology in teaching provides greater learning opportunities for students (Roberts, 2012) and the use of technology can enhance the student abilities (AlA'ali, 2008). In addition, integrating technology in the classroom helps to produce students who are visionary and have the potential and expertise in both technology and academics. Technological advances in mathematics education have paved the way for teachers to use technology to improve the quality of teaching and learning. As a result of the implementation of policies that emphasize the importance of using technology in education, all parties involved in education are faced with the important task of reforming methods of teaching and learning.

In a study by Mullis et al. (2008), approximately $20 \%$ of Malaysian students failed to achieve the minimum benchmarks in mathematics. Students fail to give accurate answers, especially in geometry. In addition, students do not understand mathematical concepts and lack necessary skills in problem-solving. Students have problems understanding basic mathematics and fundamental geometry concepts (Azlina and Suhaila, 2008). Thus, it is important for teachers to find the best way to teach mathematics. One software program that is currently available free of charge is GeoGebra. GeoGebra was designed by Mark Hohenwarter. This software is dynamic and includes geometry, algebra and calculus. GeoGebra is designed for use in mathematics education in secondary schools and higher educational institutions (Hohenwarter, 2004). GeoGebra software comes with basic object $\neg$ of object points, vectors, segments, polygons, straight lines, which are all part of a cone shape and function (Antohe, 2009; Hohenwarter, 2004) and the ability to offer various types of instruction. In addition, GeoGebra is able to perform online, interactive teaching, which allows more opportunities for teachers to upload resources for online learning (Hohenwarter $e t$ al., 2008). This software is open source, or free, to be downloaded by all users and is not subject to any

Corresponding Author: Effandi Zakaria, Department of Educational Methodology and Practices, Faculty of Education, Universiti Kebangsaan Malaysia, Bangi, Selangor, Malaysia 
license fee. In addition, GeoGebra software is designed for use in schools and educational institutions (Hohenwarter, 2004). GeoGebra is a versatile software, able to generate a picture or graphic visualization of mathematical ideas or concepts (Hohenwarter and Jones, 2007) and to display a picture or graphic on the simultaneous visualization of the window graphics, algebra and geometry (Arranz et al., 2009). Teachers also reported that GeoGebra software can generate dynamic visualizations in teaching students a particular calculus concept. Edwards and Jones (2006) found that this software is easy to use even for those who are not adept at information technology. In fact, teachers are excited by the potential use of GeoGebra to learn mathematics and are confident that this program provides effective learning experiences for students. GeoGebra software does not limit users to access either at home or at school and thus can greatly enhance learning opportunities for mathematics students. For this study, researchers will explore teachers' perceptions of GeoGebra features that were introduced during a workshop.

\section{MATERIALS AND METHODS}

This study employed a quantitative survey method that uses a questionnaire to collect data. Descriptive statistics were used to gauge teachers' perceptions toward the software during a GeoGebra workshop. A total of 30 mathematics teachers from three schools were selected as respondents. This study involved three secondary schools in the district of Sandakan, Sabah. A survey instrument to measure teachers' views was modified from Preiner (2008), ranging from 1 (Very difficult) to 5 (Very easy).

As shown in Table 1, the Cronbach's alpha values were above 0.7 , the acceptable threshold suggested by Pallant (2004).

Implementation: The structure and content of the introductory workshop consisted of four workshops as follows:

Workshop I: Basic geometric constructions: In this workshop, teachers learned to create basic geometry using GeoGebra. In addition, teachers were introduced to a dynamic geometry tool selected for certain characteristics that facilitate construction:

Activity 1: Line Bisector with GeoGebra

Activity 2: Square

Activity 3: Circumscribed Circle of a Triangle

Activity 4: Equilateral Triangle
Table 1: Reliability coefficient of each part of the questionnaire

\begin{tabular}{ll}
\hline Part of Questionnaire & Cronbach alpha \\
\hline Part A: Characteristic of GeoGebra (Introduction) & 0.937 \\
Part B: Basic geometry construction & 0.972 \\
Part C: Angle, transformation and insert image & 0.977 \\
Part D: Coordinate and equation & 0.959 \\
Part E: Function and export image & 0.955
\end{tabular}

Workshop II: The angle, transformations and pictures: In this workshop, teachers learned how to display the angle-GeoGebra corner, apply the transformation of objects available, insert a picture in a GeoGebra graphics window and use it to enhance the dynamic figure:

Activity 1: Parallelogram with Angles

Activity 2: Drawing Tool for Symmetric Figures

Activity 3: Inserting a Background Image

Activity 4: Rotation of a Polygon

Workshop III: Coordinates and equations: In this workshop, teachers learned about the algebra window and input fields in GeoGebra. In addition, teachers learned how to enter coordinates and mathematical equations to construct objects using algebraic presentation:

Activity 1: Coordinates of Points

Activity 2: Linear Equations

Activity 3: Slope Triangle

Activity 4: Quadratic Equations

Workshop IV: Functions and export of images: In this workshop, teachers learned how to handle functions using GeoGebra, exploring the concepts of calculus, the export of static images construct by the teachers and ways to incorporate these images into the text-processing software to produce teaching materials for students.

Activity 1: Polynomials Functions

Activity 2: Library of Functions

Activity 3: Tangent and Slope Function

Activity 4: Export of Static Pictures

\section{RESULTS}

Table 2 below shows the number of respondents teaching Mathematics. Sixteen (16) teachers (53.3\%) had less than five years of teaching experience. Meanwhile, nine teachers $(30 \%)$ had experience ranging from six to ten years. However, only $16.7 \%$ of teachers had ten years or more of teaching experience.

The mean score analysis was divided into three parts. The lowest mean score was between 1:00-2:33 (Difficult), the moderate score was between 2: 343.67 (Moderate) and the high score lies between 3.68 and 5.00 (Easy). 
J. Math. \& Stat., 8 (2): 253-257, 2012

Table 2: Experience in teaching mathematics

\begin{tabular}{llr}
\hline Teaching e & Frequency & \\
Experience & $-\%)$ & f \\
\hline 5 years or less & 53.3 & 16 \\
$6-10$ years & 30.0 & 9 \\
10 or more years & 16.7 & 5 \\
\hline
\end{tabular}

Table 3: Overall mean of teachers' perceptions toward GeoGebra workshop

\begin{tabular}{lccc}
\hline $\mathrm{N}$ & & $\mathrm{M}$ & $\mathrm{S} . \mathrm{D}$ \\
\hline Characteristic of algebra & 30 & 3.53 & 0.466 \\
Workshop I & 30 & 3.85 & 0.685 \\
Workshop II & 30 & 3.78 & 0.728 \\
Workshop III & 30 & 3.58 & 0.632 \\
Workshop IV & 23 & 3.59 & 0.628 \\
\hline
\end{tabular}

Table 4: Teachers' perceptions toward characteristics of GeoGebra in the Introductory Workshop

\begin{tabular}{llll}
\hline Item & & M & S.D \\
\hline I1 & Construction protocol & 3.40 & 0.563 \\
I2 & Navigation bar & 3.63 & 0.556 \\
I3 & Rename objects- & 3.67 & 0.606 \\
I4 & Context menu & 3.63 & 0.556 \\
I5 & Properties dialog & 3.43 & 0.679 \\
I6 & Grid & 3.70 & 0.702 \\
I7 & Point capturing & 3.70 & 0.702 \\
I8 & Trace of an object- & 3.47 & 0.629 \\
I9 & Background image & 3.60 & 0.563 \\
I10 & Labeling objects & 3.70 & 0.651 \\
I11 & Redefining objects & 3.50 & 0.629 \\
I12 & Auxillary objects & 3.17 & 0.699 \\
I13 & Insert static text & 3.43 & 0.679 \\
I14 & Insert dynamic text & 3.17 & 0.699 \\
I15 & Create a point on an object & 3.70 & 0.651 \\
Overall & & 3.53 & 0.466 \\
\hline
\end{tabular}

Table 3 reflects the overall mean of teachers' perceptions toward GeoGebra workshops. The findings showed that teachers' perceptions of GeoGebra features were at a moderate level $(\mathrm{M}=3.53)$. For Workshop I, the Construction of Basic Geometry was at a high level $(\mathrm{M}=3.85)$. The findings showed that teachers' perceptions about the features and tools introduced in Workshop I had the highest mean score. For Workshop II, the angle, transformation and inserting picture tools were also at a high level $(\mathrm{M}=3.78)$. For Workshop III, coordinates and equations and for Workshop IV, functions and exporting images were at a moderate level, with a mean of 3.58 and 3:59, respectively.

Table 4 shows the findings regarding teachers' perceptions toward the characteristics of GeoGebra in the Introductory Workshop. Items that had the highest mean score of 3.70 were item I6 (grid), I7 (point capturing), I10 (labeling objects) and I15 (create a point on an object), while the other eleven items were all located on a moderate level, with a mean score ranging from 3.17-3.67. Overall, it was determined that most teachers found that the tools and features of GeoGebra were easy to use.
Table 5: Teachers' perceptions toward features and tools in workshop I

\begin{tabular}{llll}
\hline Item & & M & S.D \\
\hline W1_1 & Line bisector construction with GeoGebra & 3.67 & 0.844 \\
W1_2 & Ortocenter of a triangle construction & 3.60 & 0.770 \\
W1_3 & Square of a segment & 3.47 & 0.776 \\
W1_4 & Segment through two points & 4.03 & 0.718 \\
W1_5 & Circle with center through points & 3.90 & 0.845 \\
W1_6 & Intersect two objects & 3.90 & 0.885 \\
W1_7 & Line through two points & 3.90 & 0.759 \\
W1_8 & Move & 4.07 & 0.785 \\
W1_9 & Polygon & 3.97 & 0.765 \\
W1_10 & Line bisector & 3.90 & 0.759 \\
W1_11 & Show/hide object & 3.90 & 0.845 \\
W1_12 & Move drawing pad & 3.83 & 0.834 \\
W1_13 & Zoom in... zoom out & 3.97 & 0.765 \\
W1_14 & Perpendicular line & 3.80 & 0.847 \\
Overall & & 3.85 & 0.685 \\
\hline
\end{tabular}

Table 6: Teachers perceptions toward features and tools in Workshop II

\begin{tabular}{lll}
\hline Item & M & S.D \\
\hline W2_1 Parallelogram and angles & 3.63 & 0.718 \\
W2_2 Symmetry construction & 3.57 & 0.774 \\
W2_3 Background image and axis of symmetry & 3.43 & 0.679 \\
W2_4 Rotation of a polygon & 3.47 & 0.860 \\
W2_5 Segment through two points & 3.77 & 0.935 \\
W2_6 Circle with center through point & 3.83 & 0.913 \\
W2_7 Intersect two objects & 3.93 & 0.828 \\
W2_8 Line through two points & 3.97 & 0.850 \\
W2_9 Move & 4.07 & 0.868 \\
W2_10 Polygon & 4.07 & 0.828 \\
W2_11 Show/hide object & 3.90 & 0.885 \\
W2_12 Parallel line & 3.90 & 0.885 \\
W2_13 Angle & 3.77 & 0.858 \\
W2_14 Mirror at line & 3.67 & 0.922 \\
W2_15 New point & 3.87 & 0.937 \\
W2_16 Rotate around point & 3.77 & 0.802 \\
W2_17 Insert image & 3.83 & 0.874 \\
Overall & 3.78 & 0.728 \\
\hline
\end{tabular}

Table 5 shows teachers' perceptions about the features and tools that were introduced in the first workshop on construction of basic geometry. The findings indicated that the first three items of the activities carried out during Workshop I were at a moderate level. The mean score for eleven items from W1_4 to W1_14 was high, ranging from 3.80-4.07.

Table 6 shows the activities and tools for item W2_1 to item W2_14. For item W2_1 to W2_4, teachers' perceptions were moderate. For item W2_5 to W2_13, teachers' perceptions were high, ranging from 3.77 to 4.07. The easiest activities and tools were W2_9 (Move) and W2_10 (Polygon), followed by W2_8 (Line through two points) and W2_7 (Intersect two objects).

As shown in Table 7, items W3_2, W3_3, W3_4 and W2_13 to W3_17 were at a moderate level. Nine tools were at a high level with a mean score of between 3.70 and 4.00. The highest was item W3_7, with a mean score of 4.00, followed by items W3_6 (3.93) and W3_9 (3.87) respectively. 
J. Math. \& Stat., 8 (2): 253-257, 2012

Table 7: Teachers perceptions toward features and tools in Workshop III

\begin{tabular}{llll}
\hline Item & & M & S.D \\
\hline W3_1 & Coordinates of points & 3.70 & 0.749 \\
W3_2 & Slope intercept form of a linear equation & 3.13 & 0.681 \\
W3_3 & Slope triangle & 3.30 & 0.749 \\
W3_4 & Parabola & 3.37 & 0.809 \\
W3_5 & Intersect two objects & 3.70 & 0.877 \\
W3_6 & Line through two points & 3.93 & 0.907 \\
W3_7 & Move & 4.00 & 0.830 \\
W3_8 & Polygon & 3.83 & 0.834 \\
W3_9 & Show/hide object & 3.87 & 0.776 \\
W3_10 & Perpendicular line & 3.73 & 0.868 \\
W3_11 & Parallel line & 3.80 & 0.805 \\
W3_12 & New point & 3.80 & 0.847 \\
W3_13 & Slider & 3.40 & 0.724 \\
W3_14 & Slope & 3.47 & 0.860 \\
W3_15 & Insert text & 3.60 & 0.770 \\
W3_16 & Slope & 3.00 & 0.883 \\
W3_17 & Vertex & 3.13 & 0.860 \\
Overall & & 3.58 & 0.632 \\
\hline
\end{tabular}

Table 8: Teachers' perceptions toward the features and tools in Workshop IV

\begin{tabular}{llll}
\hline Item & & M & S.D \\
\hline W4_1 & Polynomial functions & 3.30 & 0.635 \\
W4_2 & Library of functions & 3.30 & 0.635 \\
W4_3 & Tangent to a function & 3.22 & 0.671 \\
W4_4 & Export of pictures & 3.61 & 0.783 \\
W4_5 & Inserting pictures into word & 3.52 & 0.730 \\
W4_6 & Intersect two objects & 3.69 & 0.822 \\
W4_7 & Move & 3.91 & 0.848 \\
W4_8 & Show/hide object & 3.96 & 0.825 \\
W4_9 & Perpendicular line & 3.83 & 0.834 \\
W4_10 & New point & 4.04 & 0.825 \\
W4_11 & Tangent & 3.43 & 0.843 \\
W4_12 & Root & 3.48 & 0.790 \\
W4_13 & Extreme & 3.35 & 0.832 \\
Overall & & 3.59 & 0.628 \\
\hline
\end{tabular}

Table 8 shows teachers' perceptions about the features and tools of Workshop IV. The findings showed that five items were at a high level, i.e., item 6 $(\mathrm{M}=3.68)$, item $7(\mathrm{M}=3.91)$, item $8(\mathrm{M}=3.96)$, item $9(\mathrm{M}=3.83)$ and item $10(\mathrm{M}=4.04)$. The other items were at a moderate level, ranging from 3.22 to 3.61 .

\section{DISCUSSION}

Overall use of the features and tools in GeoGebra: The findings of teachers' perceptions about the features in GeoGebra are moderate. The level of difficulty of each item assessed by teachers does not exceed the mean value of 3.70. From the open-ended questionnaire, teachers gave their opinion that GeoGebra software is easier to use and is more easily understood and explored. Similar comments were made by students in a study done by Green and Robinson (2009). Three teachers reported that the software is appropriate to assist teachers in teaching and learning. However, there were teachers who expressed difficulties or problems for the command used to add dynamic text and who needed more time to learn the proper command first.

Aspect of difficulty in using GeoGebra tools during the workshop on Construction of Basic Geometry.

The findings on teachers' perceptions about features and tools in this workshop were high. Preiner (2008) reported that these workshops tend to be easier. The findings of this study were consistent with the findings of Preiner. Although all respondents in this study were new users of GeoGebra, the activities in this workshop did not cause major problems for them.

Aspect of difficulty in using GeoGebra tools during the workshop on Angle and Transformation.

The findings of teachers' perceptions toward the features and tools in this workshop are high. Premier (2008) stated that activity I was the easiest compared to the other four activities in this workshop and those findings are consistent with the findings of this study. Among the feedback from teachers about the difficulties in this area was that the presentation given by the researcher was too fast due to time constraints to finish the construction. Thus, some teachers did not have time to follow the construction steps and only looked at the construction process and these activities involve a number of new tools that are introduced.

Aspect of difficulty in using GeoGebra tools during the workshop on Coordinate and Equation.

The findings on teachers' perceptions about the features, tools and commands in this workshop are moderate. Thus, the activities in the third workshop were the most difficult. The first activity, points of coordinates, was the easiest, that is, at high levels compared to the other three activities. The findings were again consistent with the findings of Preiner (2008). Table 7, shows that three new tools introduced in this workshop were at a moderate level: slider, slope and insert text. One problem that caused difficulty in this workshop was respondents' lack of knowledge of the basic command for inserting text and the calculation of the gradient using a command. Respondents also stated that the command needed to insert the text is too complex. This feedback was also consistent with the study of Preiner (2008), indicating that the activities in this workshop were complex and challenging for respondents.

Aspect of difficulty in using GeoGebra tools during the workshop on Function and Image Export.

The findings of this workshop are moderate. These findings differ from the findings of Preiner (2008), which showed activity in the workshop was most easy. In this workshop, there were some items for which the mean was high. This was because the tools in the 
workshop were tools that had been introduced in Workshop I. Respondents also indicated that they needed more time to master the new command that was introduced in this workshop.

\section{CONCLUSION}

The findings of this study revealed that mathematics teachers in secondary schools have a positive attitude toward the use of GeoGebra. Through this discussion, we can conclude that mathematics is a subject that is abstract and that requires the collective imagination of students and teachers, particularly in the areas of geometry and transformations. The use of technology exposes students to learning without boundaries and also promotes student-centered learning, where the teacher acts as an enabler or facilitator. GeoGebra software is expected to help mathematics teachers diversify their teaching methods to facilitate students' understanding of mathematics concepts through effective teaching and learning. In addition, it is expected that GeoGebra will be used as an alternative to encourage teachers to employ technology as a means of harnessing student potential in the teaching and learning of mathematics.

\section{REFERENCES}

Al-A'ali, M., 2008. A study of mathematics web-based learning in schools. Am. J. Applied Sci., 5: 15061517. DOI: 10.3844 /ajassp.2008.1506.1517

Antohe, V., 2009. Limits of Educational Soft "GeoGebra" in a critically constructive review Ann. Comput. Sci. Series, 7: 47-54.

Arranz, J.M., R. Losada, J.A. Mora, T. Recio and M. Sada, 2009. GeoGebra on the rocks. Dynamic Geometry Geometry Learn.
Azlina, M.K. and A. Suhaila, 2008. Kesan kaedah pengajaran berbantukan Geometer's Sketchpad terhadap pencapaian pelajar dalam topik transformasi. Seminar Kebangsaan Pendidikan Sains dan Matematik.

Edwards, J.A. and K. Jones, 2006. Linking geometry and algebra with GeoGebra. MicroMath, 194: 2830.

Green, D.R. and C.L. Robinson, 2009. Introducing Geogebra to foundation year students. MSOR Connect., 9: 6-10.

Hohenwarter, J., M. Hohenwarter and Z. Lavicza, 2008. Introducing dynamic mathematics software to secondary school teachers: The case of GeoGebra. J. Comput. Math. Sci. Teach., 28: 135-146. http://editlib.org/p/30304

Hohenwarter, M. and K. Jones, 2007. Ways of linking geometry and algebra: The case of GeoGebra. Proceedings of the British Society for Research into Learning Mathematics, (BSRLM' 07), pp: 126-131.

Hohenwarter, M., 2004. Bidirectional dynamic geometry and algebra with GeoGebra.

Mullis, I.V.S., M.O. Martin, P. Foy and J.F. Olson, 2008. Trends in International Mathematics and Science Study. 1st Edn., Iea Times and Pirls, ISBN-10: 1889938483, pp: 473.

Pallant, J., 2004. SPSS Survival Manual: A Step by Step Guide to Data Analysis Using SPSS for Windows. 1st Edn., Open University Press, ISBN10: 0073013307.

Preiner, J., 2008. Introducing dynamic mathematics software to mathematics teachers: The case of GeoGebra. PhD Thesis, University of Salzburg Austria.

Roberts, G.R., 2012. Technology and learning expectations of the net generation. University of Pittsburgh, Johnstown. 